Regards sur l'économie allemande

Bulletin économique du CIRAC

$78 \mid 2006$

Varia

\title{
Opinion : les Allemands ont peur de la hausse des prix
}

Isabelle Bourgeois

\section{OpenEdition}

1 Journals

Édition électronique

URL : http://journals.openedition.org/rea/782

DOI : $10.4000 /$ rea. 782

ISBN : 978-2-8218-0852-2

ISSN : 1965-0787

\section{Éditeur}

CIRAC

Édition imprimée

Date de publication : 1 octobre 2006

Pagination : 42

ISSN : 1156-8992

Référence électronique

Isabelle Bourgeois, "Opinion : les Allemands ont peur de la hausse des prix», Regards sur l'économie allemande [En ligne], 78 | octobre 2006, document 3, mis en ligne le 01 octobre 2008, consulté le 15 septembre 2020. URL : http://journals.openedition.org/rea/782

Ce document a été généré automatiquement le 15 septembre 2020

(c) CIRAC 


\title{
Opinion : les Allemands ont peur de la hausse des prix
}

\author{
Isabelle Bourgeois
}

1 Les Allemands sont moins frileux en 2006: la reprise conjoncturelle soutient leur optimisme, et du fait de la grande coalition, les questions de politique sociale ne sont plus le point de cristallisation de conflits entre gouvernement et opposition. $\mathrm{Si}$ l'évolution macro-économique et politique a de quoi rassurer les Allemands, ils sont tout de même $63 \%$ à avoir une piètre opinion des responsables politiques à qui ils reprochent leur "manque de proximité avec les citoyens». Actuellement, ce qui les préoccupe le plus ( $70 \%$ d'entre eux), c'est l'augmentation du coût de la vie - angoisse traditionnelle outre-Rhin. S'ils sont toujours inquiets face au chômage (61\%), ils redoutent d'avoir à l'affronter personnellement (51\%), mais nettement moins que l'an dernier (65\%). Enfin, s'ils restent conscients de l'état précaire de l'Etat-Providence, ils voient l'effort de réformes et reprennent confiance en ce qui concerne les deux risques susceptibles de les affecter directement : $52 \%$ ont peur de se trouver en situation de dépendance quand ils seront âgés (contre $62 \%$ l'an dernier), $51 \%$ d'entre eux, de tomber gravement malades (64\%).

2 Les plus confiants en l'avenir sont les habitants du Bade-Wurtemberg (38\% seulement d'entre eux sont très inquiets) ; il est vrai que ce sont les plus qualifiés et les plus riches. A l'opposé, les plus angoissés se trouvent en Saxe-Anhalt (61\%), un Land au taux de chômage élevé et qui n'a pas achevé sa transition économique; s'y ajoute aussi une rémanence culturelle : nombre d'Allemands de l'est cultivent encore la nostalgie d'un Etat tout-puissant et n'ont pas totalement intégré la culture (ouest-allemande) de la responsabilité comme de l'initiative individuelles. Mais la tendance lourde la plus significative révélée par ce sondage commandité par l'assureur $\mathrm{R}+\mathrm{V}$ Versicherung (Wiesbaden) et effectué de juin à juillet auprès d'un échantillon représentatif de 2368 personnes de plus de 14 ans, est celle-ci : depuis 1991, année de lancement de cette vague annuelle de sondages (Die Ängste der Deutschen), les peurs liées aux risques extérieurs et même celles qui concernent leur situation personnelle ont baissé en comparaison des inquiétudes quant à l'évolution macro-économique et politique du 
pays. L'écart entre les premières $(32 \%)$ et les dernières $(56 \%)$ révèle la haute conscience qu'ont les citoyens allemands des enjeux globaux de compétitivité économique.

INDEX

Mots-clés : consommation, opinion publique, pouvoir d'achat, prix 